\title{
Carpentier-Edwards PERIMOUNT Magna bioprosthesis: A stented valve with stentless performance?
}

\author{
Pasquale Totaro, MD, Nello Degno, MD, Afzal Zaidi, FRCS(CTh), Aprim Youhana, FRCS(CTh),
} and Vincenzo Argano, FRCS(CTh)

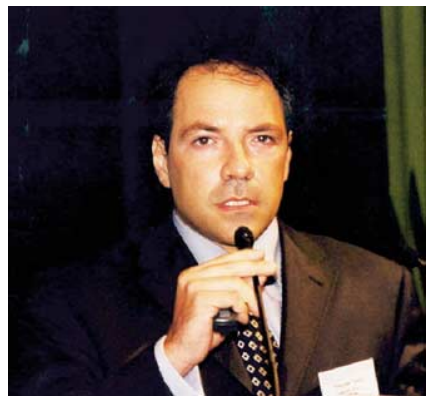

Mr Totaro
From the Cardiac Surgery Division, Regional Cardiac Centre, Morriston Hospital, Swansea, United Kingdom.

Read at the Eighty-fifth Annual Meeting of The American Association for Thoracic Surgery, San Francisco, Calif, April 10-13, 2005.

Received for publication April 8, 2005; revisions received June 10, 2005; accepted for publication July 7, 2005.

Address for reprints: Pasquale Totaro, MD, Cardiac Surgery Division, Morriston Hospital, SA6 6NL Swansea, United Kingdom (E-mail: ptotaro@yahoo.com).

J Thorac Cardiovasc Surg 2005;130:1668-74 $0022-5223 / \$ 30.00$

Copyright (c) 2005 by The American Association for Thoracic Surgery

doi:10.1016/j.jtcvs.2005.07.011
Objective: We designed this study to evaluate the early hemodynamic performance of the recently introduced Carpentier-Edwards PERIMOUNT Magna bioprosthesis (Edwards Lifesciences, Irvine, Calif) and compare it with those of the conventional Carpentier-Edwards PERIMOUNT stented bioprosthesis (Edwards Lifesciences) and Edwards Prima Plus porcine stentless bioprosthesis (Edwards Lifesciences).

Methods: Sixty-three patients ( $>70$ years old) were enrolled in this prospective, randomized study. At operation, once the annulus had been measured, the best size suitable was assessed for each of the three valves before random assignment. Transthoracic echocardiography was performed before discharge to evaluate early postoperative hemodynamic performances of the different valves implanted.

Results: The best size suitable of Edwards Prima Plus $(24.3 \pm 1.7 \mathrm{~mm})$ was significantly superior to those of both the Carpentier-Edwards PERIMOUNT Magna $(23.4 \pm 2.1 \mathrm{~mm})$ and Carpentier-Edwards PERIMOUNT $(22.4 \pm 1.8 \mathrm{~mm})$. The best size suitable of the Carpentier-Edwards PERIMOUNT Magna, however, was significantly superior to that of the Carpentier-Edwards PERIMOUNT. Furthermore the best size suitable of the Carpentier-Edwards PERIMOUNT Magna was equal to the measured annulus in 55\% of patients, as opposed to $25 \%$ for the CarpentierEdwards PERIMOUNT $(P<.001)$. Mean implanted labeled size of the Edwards Prima Plus was significantly higher than those of both the Carpentier-Edwards PERIMOUNT Magna and the Carpentier-Edwards PERIMOUNT (24.6 $\pm 1.9 \mathrm{~mm}$, $23.1 \pm 1.9 \mathrm{~mm}$, and $22.5 \pm 1.8 \mathrm{~mm}$, respectively). Early postoperative hemodynamic performance of the Carpentier-Edwards PERIMOUNT Magna, however, was superior to those of both the Edwards Prima Plus and the Carpentier-Edwards PERIMOUNT in both effective orifice area index $\left(1.07 \pm 0.4 \mathrm{~cm}^{2} / \mathrm{m}^{2}, 0.87 \pm 0.3\right.$ $\mathrm{cm}^{2} / \mathrm{m}^{2}$, and $0.80 \pm 0.2 \mathrm{~cm}^{2} / \mathrm{m}^{2}$, respectively) and mean peak gradient ( $20 \pm 6 \mathrm{~mm} \mathrm{Hg}$, $27 \pm 8 \mathrm{~mm} \mathrm{Hg}$, and $28 \pm 12 \mathrm{~mm} \mathrm{Hg}$, respectively).

Conclusion: The improved design of the recently introduced third-generation stented bioprosthesis Carpentier-Edwards PERIMOUNT Magna allows implantation of a significantly bigger valve than with the old generation. Furthermore, the improved hemodynamic performance of the Carpentier-Edwards PERIMOUNT Magna compares favorably with both the Carpentier-Edwards PERIMOUNT and the Edwards Prima Plus.

$\mathrm{T}$ here is general agreement that a bioprosthesis should be the prosthesis of choice for aortic valve replacement (AVR) in the elderly population; however, debates are ongoing regarding which type of bioprosthesis should be preferred. Since their introduction in the late 1980s, ${ }^{1}$ stentless bioprostheses have been proposed as the best choice for AVR in elderly patients to improve postoperative hemodynamic performance and reduce the risk of patient-prosthesis mismatch., ${ }^{2,3}$ Several studies have tried to elucidate benefits of stentless valves 


\author{
Abbreviations and Acronyms \\ $\mathrm{AVR}=$ aortic valve replacement \\ CEP $=$ Carpentier-Edwards PERIMOUNT stented \\ bioprosthesis \\ $\mathrm{EOA}=$ effective orifice area \\ $\mathrm{LVM}=$ left ventricular mass \\ PEM $=$ Carpentier-Edwards PERIMOUNT Magna \\ stented bioprosthesis \\ PPS = Edwards Prima Plus stentless porcine \\ bioprosthesis
}

relative to stented bioprostheses, and contrasting results have been reported so far. Recent randomized studies ${ }^{4,5}$ have failed to confirm significant benefits of stentless valves previously reported from nonrandomized studies. ${ }^{6-13}$ Furthermore, a new generation of stented bioprosthesis has been recently introduced with claims of improved hemodynamic performance. We designed this study to evaluate the early hemodynamic performance of the recently introduced Carpentier-Edwards PERIMOUNT Magna stented bioprosthesis (PEM; Edwards Lifesciences, Irvine, Calif) and compare it with those of two frequently used bioprostheses, the conventional Carpentier-Edwards PERIMOUNT stented bioprosthesis (CEP; Edwards Lifesciences) and the Edwards Prima Plus stentless porcine bioprosthesis (PPS; Edwards Lifesciences). We decided to compare different prostheses from the some company to reduce the bias related to different ratios between labeled size and internal diameter seen when comparing different bioprosthesis from different companies. ${ }^{14}$

\section{Patients and Methods}

Sixty-three patients ( $>70$ years old) requiring AVR were enrolled at our institution into this prospective, randomized study during a period of 18 months. Patients requiring urgent or additional surgical procedures other then coronary artery bypass grafting were excluded from the study, along with those with poor left ventricular function (ejection fraction $<30 \%$ ).

\section{Study Design}

The study was approved by the local ethics committee. After written, informed consent was provided, patients matching the inclusion criteria were enrolled in the study. Specific anatomic contraindications to stentless valve implantation (eg, excessive aortic calcifications, bicuspid native aortic valve, coronary anomalies) were evaluated during the operation. In the presence of specific contraindications, the patient was withdrawn from the study.

After excision of the native valve, the annulus was thoroughly decalcified and measured with a universal (Hegar) sizer. Once the best size suitable had been assessed for each of the three valves, random assignment was disclosed.

\section{Valve Characteristics}

The CEP (bovine pericardial stented bioprosthesis) and PPS (porcine stentless bioprosthesis) are well-known prostheses extensively described in previous studies. ${ }^{15-19}$ The PEM is a newer generation bovine pericardial stented bioprosthesis recently introduced to the market. It is characterized by a new supra-annular design that is claimed to have better hemodynamic and flow characteristics. The recently Food and Drug Administrationapproved original ThermaFix decalcification process (Edwards Lifesciences) is also expected to improve the long-term durability.

\section{Surgical Technique}

All operations were carried out through a standard midline sternotomy with cardiopulmonary bypass (after standard ascending aorta and right atrium cannulation) with moderate hypothermia $\left(32^{\circ} \mathrm{C}\right)$. Myocardial protection was obtained in all cases with an initial infusion of cold blood cardioplegia, with additional maintenance doses every 15 to 20 minutes.

The selected valve was implanted according two different techniques. PPSs were implanted with a standard subcoronary technique with a $120^{\circ}$ rotation of the valve. Interrupted single sutures of unpledgetted 4-0 polyester (Ethibond; Ethicon, Inc, Somerville, NJ) were used for the inflow, and running 4-0 polypropylene sutures (Prolene; Ethicon) were used for the outflow. Both CEP and PEM bioprostheses were implanted in the supra-annular position with interrupted, radial, noneverting, unpledget-supported 2-0 polyester sutures (Ethibond; Ethicon, or Ti-Cron [SherwoodDavis \& Geck, St Louis, Mo]).

\section{Postoperative Evaluation}

Hemodynamic performance of each valve implanted was evaluated before patient discharge with transthoracic echocardiography performed by a senior technician who was blinded to the type of prosthesis used. Effective orifice area (EOA), peak and mean pressure gradients, left ventricular ejection fraction, and cardiac output were calculated according to standard formulas previously published. ${ }^{5,15,16}$

\section{Statistical Analysis}

Data are reported as mean $\pm \mathrm{SD}$. Normal distribution was tested by Kolmogorov-Smirnov test. Categoric data were compared with either the $\chi^{2}$ or Fisher exact test, with Yates correction applied when appropriate. Continuous variables were compared by analysis of variance. Correlation between increasing size and improved EOA was established by linear regression model. SPSS application software version 11.5 (SPSS Inc, Chicago, Ill) was used for statistical analysis.

\section{Results}

Of 63 patients enrolled, 3 were withdrawn before random assignment because of specific contraindications to stentless valve implantation. Preoperative characteristics of the 60 patients who entered the randomization are summarized in Table 1. Although the difference in body surface area approached statistical significance, the intraoperative annulus measurements did not differ among the three groups $(24.2$ $\pm 1.7 \mathrm{~mm}, 23.9 \pm 1.6 \mathrm{~mm}$, and $24.3 \pm 1.9 \mathrm{~mm}$ for PEM, CEP, and PPS, respectively). As far as the specific valve 
TABLE 1. Preoperative characteristics $(n=60)$

\begin{tabular}{lcccc}
\hline & PEM & CEP & PPS & P value \\
\hline Patients (No.) & 20 & 20 & 20 & \\
Sex (No.) & & & & .717 \\
$\quad$ Male & $12(60 \%)$ & $9(45 \%)$ & $7(35 \%)$ & \\
$\quad$ Female & $8(40 \%)$ & $11(55 \%)$ & $13(65 \%)$ & .382 \\
Age (y, mean \pm SD) & $73 \pm 4$ & $74 \pm 4$ & $73 \pm 5$ & .07 \\
Body surface area (m², mean \pm SD) & $1.78 \pm 0.19$ & $1.86 \pm 0.2$ & $1.71 \pm 0.2$ & .713 \\
Aortic valve area (cm², mean \pm SD) & $0.63 \pm 0.3$ & $0.65 \pm 0.2$ & $0.62 \pm 0.2$ & .706 \\
Transaortic gradient (mm Hg, mean \pm SD) & $101 \pm 24$ & $100 \pm 20$ & $103 \pm 21$ & .768 \\
$\quad$ Peak & $59 \pm 23$ & $60 \pm 16$ & $58 \pm 10$ & .865 \\
$\quad$ Mean & $59 \% \pm 24 \%$ & $60 \% \pm 7 \%$ & $59 \% \pm 15 \%$ & .122 \\
Left ventricular ejection fraction (\%, mean \pm SD) & $10(50 \%)$ & $5(25 \%)$ & $11(55 \%)$ & \\
AVR plus coronary artery bypass grafting (No.) & & & &
\end{tabular}

sizing was concerned (Table 2), PPS had a better best size suitable than did either of the two stented bioprosthesis. The best size suitable of the PEM, however, was significantly better than that of CEP. Furthermore, looking at the best size suitable and annular measurement, we found in the PEM group a significantly larger percentage of patients with a best size suitable equal to the annular measurement than in the CEP group. The mean implanted size of the prosthesis reflected the differences of the best size suitable. As shown in Table 3, mean size of implanted PPS (24.6 $\pm 1.9 \mathrm{~mm})$ was significantly superior to those of both PEM $(23.1 \pm 1.9$ $\mathrm{mm})$ and CEP $(22.5 \pm 1.8 \mathrm{~mm})$. The difference between PEM and CEP failed to reached statistical significance; however, the percentage of patients receiving a PEM of the same size of the annulus (50\%) was significantly higher than in the CEP group (15\%). With respect to operative parameters, PPS relative to PEM and CEP required significantly prolonged cardiopulmonary bypass time $(161 \pm 44$ minutes, $116 \pm 44$ minutes, and $93 \pm 36$ minutes, respectively) and aortic crossclamp time (111 \pm 29 minutes, $80 \pm$ 30 minutes, and $67 \pm 27$ minutes, respectively). One patient (PPS group) died within 30 days of the operation (cumulative 30-day mortality 1.6\%), and 1 patient (CEP group) required hemofiltration. Postoperative hemodynamic performances were obtained from 56 patients, because the deceased patient and 3 patients ( 1 each group) in atrial fibrillation at the time of discharge were not considered. Mean postoperative EOA and EOA index of patients receiving PEM compared favorably with those of patients receiving both CEP and PPS (Table 4). Furthermore, patient-prosthesis mismatch (according to the definition of patient-prosthesis mismatch as EOA index $<0.85 \mathrm{~cm}^{2} / \mathrm{m}^{2}$ ) was less likely with PEM. The peak transvalvular gradient of PEM was also significantly reduced relative to CEP and PPS, whereas mean gradient did not differ significantly among the three valves. Although a complete size-by-size analysis of the hemodynamic performance for each valve was not possible because of the limited number of patients in each group, a significant correlation was seen between increasing valve size and improved EOA for PEM but not for PPS (the latter value, however, did approach statistical significance) or CEP (Figure 1). Finally, the ratio between postoperative in vivo EOA and in vitro EOA for any given size was significantly better for PEM than for both CEP and PPS $(0.92 \pm 0.09,0.81 \pm$ 0.11 , and $0.82 \pm 0.09$, respectively, $P<.05$ for PEM vs CEP and PEM vs PPS).

\section{Discussion}

The valve of choice for AVR in the elderly population is still under discussion. First-generation stented bioprosthe-

TABLE 2. Best size suitable evaluation: Comparison of annular measurement and best size suitable for the three valves in all patients

\begin{tabular}{|c|c|c|c|c|}
\hline & PEM & CEP & PPS & $P$ value* \\
\hline Annulus (mm, mean $\pm \mathrm{SD}$ ) & $24.1 \pm 1.8$ & $24.1 \pm 1.8$ & $24.1 \pm 1.8$ & \\
\hline Best size suitable $(\mathrm{mm}$, mean $\pm \mathrm{SD})$ & $23.4 \pm 2.1$ & $22.4 \pm 1.8$ & $24.3 \pm 1.7$ & .0001 \\
\hline Relationship of best size suitable to annulus (No.) & & & & .0001 \\
\hline Same size & $33(55 \%)$ & $10(25 \%)$ & $58(96 \%)$ & \\
\hline Undersized & $27(45 \%)$ & $50(75 \%)$ & $0(0 \%)$ & \\
\hline Oversized & $0(0 \%)$ & $0(0 \%)$ & $2(4 \%)$ & \\
\hline
\end{tabular}

*PPS versus PEM, PPS versus CEP, and PEM versus CEP. 
TABLE 3. Comparison of annular measurement and size of valve implanted ( $n=20$ patients per group)

\begin{tabular}{lcccc}
\hline & PEM & CEP & PPS & P value \\
\hline $\begin{array}{l}\text { Size implanted per } \\
\text { label }\end{array}$ & & & & \\
Mean \pm SD & $23.1 \pm 1.9$ & $22.5 \pm 1.8$ & $24.6 \pm 1.9$ & $.002^{*}$ \\
Median & 23 & 21 & 25 & \\
$\quad$ Mode & 23 & 21 & 23 & \\
Relationship of & & & & $.0001 \dagger$ \\
size implanted & & & & \\
to annulus & & & & \\
$\quad$ (No.) & & & & \\
Same size & $10(50 \%)$ & $3(15 \%)$ & $19(95 \%)$ & \\
Undersized & $10(50 \%)$ & $17(85 \%)$ & $0(0 \%)$ & \\
Oversized & $0(0 \%)$ & $0(0 \%)$ & $1(5 \%)$ &
\end{tabular}

*PPS versus CEP and PPS versus PEM. †PPS versus PEM, PPS versus CEP, and PEM versus CEP.

sis, introduced in $1965,{ }^{20}$ have provided satisfactory clinical results but limited durability ${ }^{21,22}$ and suboptimal hemodynamic performance in specific settings (small aortic annulus). To overcome some of these problems, stentless bioprosthesis were introduced in the late $1980 \mathrm{~s}^{1}$ and have been considered by many authors the prosthesis of choice even if a more demanding technique of implantation is necessary. ${ }^{2,3}$ Despite several published studies comparing the early and long-term results of patients receiving stented versus stentless bioprostheses, a clear and unanimous identification of the prosthesis of choice has not yet been reached. Implantation of a bigger size prosthesis, ${ }^{6}$ better hemodynamic performance either at rest or during maximal exercise,,, 8 and improved left ventricular mass (LVM) regression ${ }^{9,10}$ have been shown in nonrandomized trials after stentless valve implantation. Furthermore, improved postoperative survival was reported by David and colleagues ${ }^{11}$ and then confirmed by Westaby and associates ${ }^{12}$ and Luciani and colleagues. ${ }^{13}$ Recent randomized studies by Doss and coworkers ${ }^{4}$ and Cohen and associates, ${ }^{5}$ however, have yielded

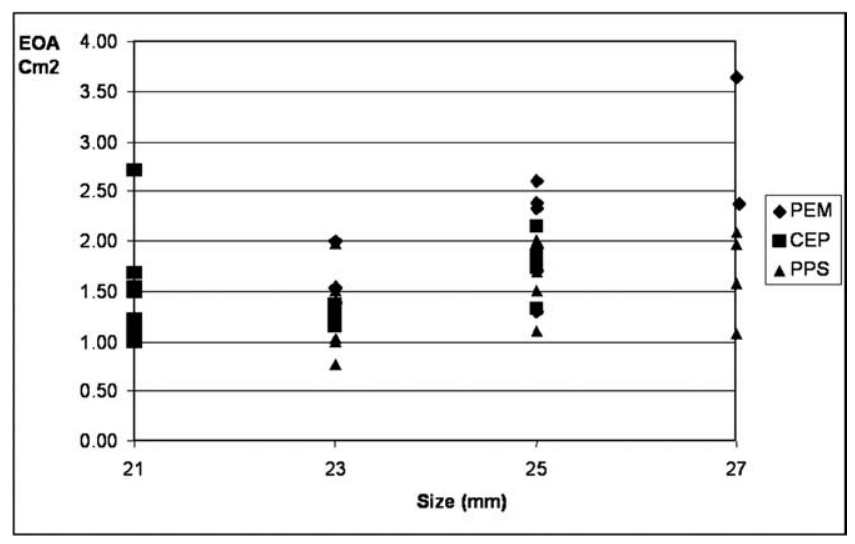

Figure 1. Linear regression analysis: labeled size of valve bioprosthesis versus EOA (PEM $r=0.54, P<.05$; CEP $r=0.25, P>$ $.05 ;$ PPS $r=0.47, P>.05)$.

contrasting results showing no significant differences in terms of hemodynamic performance and LVM regression.

The introduction of newer generation stented bioprosthesis with claims of improved hemodynamic performance has added fuel to the current controversies. ${ }^{10}$ The aim of our study was to evaluate the early hemodynamic performance of the third-generation PEM with a specific supra-annular design and a new decalcification treatment. We decided to compare its performance with those of the previous generation of the same valve (CEP) and the porcine stentless valve made by the same company (PPS). The CEP has been used for more than 15 years, and its excellent hemodynamic performances and long-term clinical results have been clearly reported. ${ }^{15,16}$ The PPS is a stentless porcine valve introduced in the early 1990s. Despite preliminary results reporting controversial performance, ${ }^{17,18}$ recent studies have confirmed good medium-term hemodynamic and clinical results. ${ }^{19}$ In fact, as previously reported for other stentless valves, ${ }^{23,24}$ the performance of the PPS appears to significantly improve after the first year.

TABLE 4. Early postoperative hemodynamic performance as evaluated by transthoracic echocardiography $(\mathrm{n}=54)$

\begin{tabular}{|c|c|c|c|c|}
\hline & PEM & CEP & PPS & $P$ value \\
\hline Patients (No.) & 19 & 19 & 18 & \\
\hline $\mathrm{EOA}\left(\mathrm{cm}^{2}\right.$, mean $\left.\pm \mathrm{SD}\right)$ & $1.92 \pm 0.8$ & $1.48 \pm 0.8$ & $1.47 \pm 0.4$ & .087 \\
\hline EOA indext $\left(\mathrm{cm}^{2} / \mathrm{m}^{2}\right.$, mean $\left.\pm \mathrm{SD}\right)$ & $1.07 \pm 0.4$ & $0.80 \pm 0.2$ & $0.87 \pm 0.3$ & $.028^{*}$ \\
\hline $\begin{array}{l}\text { Patient-prosthesis mismatch (No., EOA index } \\
\quad<0.85 \mathrm{~cm}^{2} / \mathrm{m}^{2} \text { ) }\end{array}$ & $3(15 \%)$ & $9(47 \%)$ & $5(27 \%)$ & .102 \\
\hline \multicolumn{5}{|l|}{ Transaortic gradient (mm Hg, mean \pm SD) } \\
\hline Peak & $20 \pm 6$ & $28 \pm 12$ & $27 \pm 8$ & $.017^{*} \ddagger$ \\
\hline Mean & $10 \pm 4$ & $13 \pm 6$ & $12 \pm 4$ & .153 \\
\hline Left ventricular ejection fraction $(\%$, mean \pm SD) & $57 \pm 13$ & $56 \pm 11$ & $59 \pm 11$ & .733 \\
\hline
\end{tabular}

*PEM versus CEP. $†$ Ratio of EOA to body surface area. $\$$ PEM versus CEP and PEM versus PPS. 
The first important finding of our study is that PEM allows a larger stented bioprosthesis to be implanted; in fact, $50 \%$ of patients received a valve the same size as the annulus, versus $15 \%$ in the CEP group. Despite the previously reported difficulties in comparing labeled size between different bioprostheses, ${ }^{14}$ this finding is certainly important because these two valves have the same internal diameter for a given labeled size.

The analysis of the early postoperative performance shows a second important finding: the early hemodynamic performance of PEM compared favorably with those of the other two valves in this study. Values in our study of early postoperative EOA and peak transvalvular gradient for CEP and PPS were similar to those reported in previous studies, ${ }^{10,14-16,25}$ (although Doss and coworkers ${ }^{4}$ recently reported better hemodynamic parameters for CEP); thus the performance of the PEM appears really encouraging. Although the accuracy of echocardiographically calculated EOA has been continually questioned since its introduction in the early $1990 \mathrm{~s},{ }^{26}$ it and EOA index remain the parameters most frequently used to evaluate the efficacy of a valve bioprosthesis and seem to be the only useful way to define patient-prosthesis mismatch. The small number of patients in each group made a size-by-size statistical analysis difficult; however, the statistically significant correlation between increasing size and improved EOA for PEM seems to indicate that the benefits of PEM are not limited to small valves. With respect to the incidence of patient-prosthesis mismatch (according to the accepted definition of patientprosthesis mismatch as EOA index $<0.85 \mathrm{~cm}^{2} / \mathrm{m}^{2}$ ), PEM seems to allow further benefits relative to CEP. In our experience, the incidence of patient-prosthesis mismatch after CEP implantation was slightly high; however, a similar tendency has been previously reported by Jamieson and associates. ${ }^{25}$ Furthermore, we should also consider that the mean body surface area in our series was superior to figures reported in other studies, thus affecting the estimation of postoperative patients-prosthesis mismatch. Finally, the benefit of the innovative design of the PEM is also demonstrated by its significantly superior ratio between postoperative in vivo EOA and in vitro EOA published by the company. A good correlation between in vivo and in vitro EOA has been previously shown, although the in vivo value is generally less than the in vitro value. ${ }^{27}$ In our series, the ratio in vivo to in vitro EOA was significantly superior for PEM relative to CEP. Considering that CEP had previously shown superior in vitro performance relative to other stented bioprostheses, ${ }^{28}$ we speculate that the design of the PEM allows a more complete and physiologic use of the valve area. In our series, early postoperative hemodynamic performance of the PEM also compared favorably with that of the PPS; however, determination of a real difference between PEM and PPS requires further clarification with a long-term control because of the proven improved performance of PPS after the first year after implantation. ${ }^{18,19}$

In conclusion, our study confirmed good early postoperative hemodynamic performance for CEP and PPS but also demonstrated the innovative design and clear advantage of PEM relative to the previous generation CEP. We believe that the differences seen in this study favor the PEM significantly and should be considered carefully when choosing a bioprosthesis for AVR in an elderly patient, especially one with a small annulus. Long term-results, however, are required to clarify whether the improved early hemodynamic performance of this newer generation stented bioprosthesis will allow regression of LVM comparable to those obtained after implantation of a stentless valve.

\section{Study Limitations}

The limited number of patients in each group did not allow a complete size-by-size analysis of hemodynamic performance for the different valves. Furthermore, the study focused on early postoperative hemodynamic performance, and the impact of the previously demonstrated late improvement in hemodynamic performance of stentless valves has therefore not been evaluated. For the same reason, we could not analyze the effect of the improved hemodynamic performance on LVM regression.

We thank Sabino Scolletta, MD, from Department of Cardiothoracic Surgery and Biomedical Science at University Hospital of Siena, Siena, Italy, for the statistical analysis.

\section{References}

1. David TE, Ropchan GC, Butany JW. Aortic valve replacement with stentless porcine bioprostheses. J Thorac Cardiovasc Surg. 1990;99: 113-8.

2. Sintek CF, Fletcher AD, Khonsari S. Stentless porcine root. Valve of choice for elderly patients with small aortic root. J Thorac Cardiovasc Surg. 1995;109:871-6.

3. Akar AR, Szafraneck A, Alexious C, Janas R, Jasinski MJ, Swanevelder $\mathrm{J}$, et al. Use of stentless xenografts in the aortic position: determinants of early and late outcome. Ann Thorac Surg. 2002;74: $1450-8$.

4. Doss M, Martens S, Wood JP, Aybek T, Kleine P, Wimmer Greinecker $\mathrm{G}$, et al. Performance of stentless versus stented aortic valve bioprostheses in the elderly patient: a prospective randomized trial. Eur J Cardiothorac Surg. 2003:23:299-304.

5. Cohen G, Christakis GT, Joyner CD, Morgan CD, Tamariz M, Hanayama N, et al. Are stentless valves hemodynamically superior to stented valves? A prospective randomized trial. Ann Thorac Surg. 2002;73:767-78

6. Rao V, Christakis G, Sever J, Fremes S, Bhatnagar G, Cohen G, et al. A novel comparison of stentless versus stented valves in the small aortic root. J Thorac Cardiovasc Surg. 1999;117:431-8.

7. Casabona R, De Paulis R, Zattera GF, Di Summa M, Bottone W, Stacchino $\mathrm{C}$, et al. Stentless porcine and pericardial valve in aortic position. Ann Thorac Surg. 1992;54:681-5.

8. Pibarot J, Dumesnil JG, Jobin J, Cartier P, Honos G, Durand LG. Hemodynamic and physical performance during maximal exercise in patients with an aortic bioprosthesis valve: comparison of stentless versus stented bioprostheses. J Am Coll Cardiol. 1999;34:1609-17.

9. Del Rizzo DF, Goldman BS, Christakis GT, David TE. Hemodynamic benefits of the Toronto Stentless Valve. J Thorac Cardiovasc Surg. 1996;112:1431-46. 
10. Milano AD, Blanzola C, Mecozzi G, D’Alfonso A, De Carlo M, Nardi C, et al. Hemodynamic performance of stented and stentless aortic bioprostheses. Ann Thorac Surg. 2001;72:33-8.

11. David TE, Puschmann R, Ivanov J, Bos J, Armstrong S, Feindel CM, et al. Aortic valve replacement with stentless and stented porcine valves: a case-match study. J Thorac Cardiovasc Surg. 1998;116: 236-41.

12. Westaby S, Horton M, Jin XY, Katsumata T, Ahmed O, Saito S, et al. Survival advantage of stentless aortic bioprosthesis. Ann Thorac Surg. 2000;70:785-91.

13. Luciani GB, Casali G, Auriemma S, Santini F, Mazzucco A. Survival after stentless and stented xenograft aortic valve replacement: a concurrent, controlled trial. Ann Thorac Surg. 2002;74:1443-9.

14. Eichinger WB, Botzenhardt F, Guenzinger R, Bleiziffer S, Keithahn A, Bauernschmitt $\mathrm{R}$, et al. The effective orifice area/patient aortic annulus area ratio: a better way to compare different bioprostheses? A prospective randomized comparison of the Mosaic and Perimount bioprostheses in the aortic position. J Heart Valve Dis. 2004;13:382-9.

15. Dellgren G, David TE, Raanani E, Armstrong S, Ivanov J, Rakowski $\mathrm{H}$. Late hemodynamic and clinical outcomes of aortic valve replacement with the Carpentier-Edwards Perimount pericardial bioprosthesis. J Thorac Cardiovasc Surg. 2002;124:146-54.

16. Banbury MK, Cosgrove DM, Thomas JD, Blackstone EH, Rajeswaran $\mathrm{J}$, Okies E, et al. Hemodynamic stability during 17 years of the Carpentier-Edwards aortic pericardial bioprosthesis. Ann Thorac Surg. 2002;73:1460-5.

17. Dossche K, Vanermen H, Wellens F, De Geest R, Degrieck I, Deloof T. Free-hand sewn allograft, stentless (Prima Edwards) and stented (CESE) porcine bioprostheses. A comparative hemodynamic study. Eur J Cardiothorac Surg. 1995;9:562-7.

18. Bortolotti U, Scioti G, Milano A, Borzoni G, Nardi C, Tartarini G. The Edwards Prima stentless valve: hemodynamic performance at one year. Ann Thorac Surg. 1999;68:2147-51.

19. Jin XY, Dhital K, Bhattacharya K, Pieris R, Amarasena N, Pillai R. Fifth-year hemodynamic performance of the Prima stentless aortic valve. Ann Thorac Surg. 1998;66:805-9.

20. Binet JP, Duran CG, Carpentier A, Langlois J. Heterologous aortic valve transplantation. Lancet. 1965;2:1275.

21. Jamieson WR, Munro AI, Miyagishima RT, Allen P, Burr LH, Tyers GF. Carpentier-Edwards standard porcine bioprosthesis: clinical performance to seventeen years. Ann Thorac Surg. 1995;60: 999-1007.

22. Fann JI, Miller DC, Moore KA, Mitchell RS, Oyer PE, Stinson EB, et al. Twenty-year clinical experience with porcine bioprosthesis. Ann Thorac Surg. 1996;62:1301-2.

23. Del Rizzo DF, Goldman BS, Christakis GT, David TE. Hemodynamic benefits of the Toronto stentless valve. J Thorac Cardiovasc Surg. 1996;112:1431-46.

24. Jin XY, Westaby S, Gibson DG, Pillai R, Taggart D. Left ventricular remodelling and improvement in Freestyle stentless valve hemodynamics. Eur J Cardiothoracic Surg. 1997;12:63-9.

25. Jamieson WR, Janusz MT, MacNab J, Henderson C. Hemodynamic comparison of second- and third-generation stented bioprostheses in aortic valve replacement. Ann Thorac Surg. 2001;71 (5 Suppl): S282-4.

26. Dumesnil JG, Honos GN, Lemieoux M, Beauchemin J. Validation and application of indexed aortic prosthetic valve areas calculated by Doppler echocardiography. J Am Coll Cardiol. 1990;16:637-43.

27. Reimold SC, Yoganathan AP, Sung HW, Cohn LH, Sutton MG, Lee RT. Doppler echocardiographic study of porcine bioprosthetic heart valves in the aortic valve position in patients without evidence of cardiac dysfunction. Am J Cardiol. 1991;67:611-5.

28. Marquez S, Hon RT, Yoganathan AP. Comparative hydrodynamic evaluation of bioprosthetic heart valves. J Heart Valve Dis. 2001;10: 802-11.

\section{Discussion}

Dr Neal Kon (Winston-Salem, NC). I congratulate Totaro and colleagues on this randomized, prospective trial of three different tissue bioprostheses. They concluded that the new PEM valve is the prosthesis of choice in the elderly population on the basis of differences in discharge gradients and EOAs. The new PEM valve has a less bulky stent by $2 \mathrm{~mm}$ than the older CEP valve and does not have a portion of the valve prosthesis that protrudes into the left ventricular outflow tract. This appears to allow implantation of a larger valve in the same size aortic annulus.

With regard to the stentless counterpart, PPS, when an even larger valve could be implanted in the same size annulus, the gradients were even higher and the EOAs were even smaller. Let me address why I believe the stentless valve was treated unfairly in this study, which resulted in stentless gradients higher than seen in other published studies.

As mentioned in the article, one of the limitations of this study is that the only hemodynamic parameters measured were measured at the time of discharge from the hospital, early after the operation. It is well documented in the literature that the early hemodynamics of a stentless valve should be evaluated at the 3- to 6-month interval, because the gradients drop significantly during this time frame when using a subcoronary technique.

Also, relative to the annulus size, the study used larger size stentless valves with a subcoronary technique. This too can lead to higher gradients, because you may simply be stuffing more tissue inside the same size aortic root. It is analogous to using a bulkier stent.

A root replacement technique for the stentless valve-as is used with homograft valves, autograft valves, and some stentless valves-would, I believe, result in less turbulent flow, lower gradients, and larger EOAs. The result with the root technique would be hemodynamics comparable to those in people without any valvular heart disease at all, and that particular approach would be worthwhile for the patient with a small aortic annulus.

Mr Totaro, there is fear among many surgeons of placing a larger stented valve in the same size annulus. In particular, they fear tearing the aortic root, difficulty seating the valve, obstructing low lying coronary ostia, and distortion of the bioprosthesis, possibly producing some aortic insufficiency. There were no data in the presentation or article about aortic insufficiency. Can you give us some indication of the incidence of aortic insufficiency in your study and some technical tips that you use in seating a larger stented valve in the same size annulus? And what do you recommend regarding a supra-annular implantation technique in patients who have low-lying coronary arteries?

Finally, knowing the specific drawbacks of evaluating a stentless valve with just discharge echocardiographic data, do you really think you can make stentless valve comparisons in this particular study?

Mr Totaro. Professor Kon, it is a privilege for us to have you as primary discussant. I would like to thank you for your kind comments and interesting questions.

With respect to your first comment about the unfair treatment received by the stentless valve in this study, I stressed in the presentation that the lack of medium-term follow-up is one of the limitations of this study. We are aware that performance of the stentless valve improves after 6 to 12 months from implantation and, therefore, the conclusion of our study places more stress on the differences between the PEM and the CEP than on differences with the stentless valve. 
As far as your comment on the technique of implantation used for the stentless valve, we definitely share your concern about oversizing stentless valves with a subcoronary technique; therefore, we only oversized the valve in 1 patient with a large sinotubular junction.

We are also aware of the potential benefit of the mini-root technique compared with subcoronary implantation, but we decided to use the technique more frequently reported in the literature for this valve.
We did not experience postoperative aortic insufficiency (other than trivial). With respect to oversizing stented valves, once more we share your concern. We purposely did not oversize the valve in any of the patients and the smallest valve implanted was $21 \mathrm{~mm}$. This was possibly due to the surgical technique used (radial single unpledgetted suture) that avoids any purse-string effect.

Finally, we are planning to continue the study and to present the comparison of hemodynamic performance at medium-term results.

\section{Availability of Journal back issues}

As a service to our subscribers, copies of back issues of The Journal of Thoracic and Cardiovascular Surgery for the preceding 5 years are maintained and are available for purchase from Elsevier Inc. until inventory is depleted. Please write to Elsevier Inc.,Subscription Customer Service, 6277 Sea Harbor Dr, Orlando, FL 32877 , or call $800-654-2452$ or $407-345-4000$ for information on availability of particular issues and prices. 